\title{
Knowledge, Attitude and Awareness of Medical Students towards Medico-Legal Autopsy in Sangli, Maharashtra
}

\author{
Anand Patil ${ }^{1}$, Vijay N. Tasgaonkar ${ }^{2}$, Dileep Kumar R. ${ }^{3}$, \\ Rajshekhar Myageri ${ }^{4}$, Suchita V. Magdum ${ }^{5}$ \\ ${ }^{1}$ Assistant Professor, Department of Forensic Medicine \& Toxicology, GIMS, Gadag, ${ }^{2}$ Associate Professor, \\ Department of Forensic Medicine \& Toxicology, BKLWMC \& H, Sawarda, ${ }^{3}$ Assistant Professor, Department of \\ Forensic Medicine \& Toxicology, Sri Siddhartha Medical College, Tumkur, ${ }^{4}$ Associate Professor, Department \\ of Forensic Medicine \& Toxicology, GIMS, Gadag, ${ }^{5}$ Tutor, Department of Forensic Medicine \& Toxicology, \\ BVDUMC \& H, Sangli
}

\begin{abstract}
For centuries, autopsy has been instrumental in establishing the cause of death both in clinical and forensic cases. Even though it helps in arriving at a decision regarding the cause of death and many other things, its use is declining recently, which should be a cause of concern. With this background, the present study has been carried out in January 2020 on 150 medical students of $2^{\text {nd }}$ year MBBS by using set of questionnaires, to assess their knowledge and attitude towards autopsy at department of Forensic Medicine and Toxicology at BVDU \& MC, Sangli, Maharashtra. This study shows the students had a reasonable knowledge and good attitude towards medico-legal autopsy. Majority of the students agreed that need of autopsy in all unnatural, sudden, unexpected and suspicious death is mandatory and collection of viscera for histo-pathological and toxicological analysis is useful. Majority of the students think that autopsy helps in solving crimes and gives information to police. Most of the study population shows interest in attending and performing a greater number of autopsies. Majority of the students agreed that post mortem examination is useful in medical education. Majority of the study population says that autopsy is disrespect to human body. Most of the study population is not aware of virtual autopsy.
\end{abstract}

Keywords: Medico-legal autopsy, Medical students, Medical education and Forensic medicine.

\section{Introduction}

Autopsy in Greek means "to see with one's own eyes". Medico-legal autopsy is a scientific study of a dead body and is categorized into clinical and medicolegal autopsies. It plays a crucial role in finding out the cause and the time of death, possible medico-legal issues surrounding death, providing data on disease and injury and also aiding in administration of justice. Doctors with poor knowledge in autopsy may result in injustice ${ }^{1}$. The

\section{Corresponding Author:}

\section{Dr. Rajshekhar Myageri}

Associate Professor, Department of Forensic Medicine \& Toxicology, GIMS, Gadag

Tel. +919986028269

e-mail: myagse@gmail.com use of autopsy in medical education has been declining; just as autopsy rate has been falling worldwide this is further worsened by authorities deterring medical students from attending autopsy sections in some areas ${ }^{2}$.

In India, according to the curriculum of the Medical Council of India, a medical student should witness a minimum number of medico legal autopsies in the second year so that they can observe and interpret various findings ${ }^{3}$. It is only when students attend an autopsy section, they can appreciate the large number of pathological conditions in different patients. An intern is supposed to acquire the skill of doing a medico-legal autopsy. Thus, every medical graduate is presumed to be capable of doing a medico-legal autopsy after registering as medical practitioner ${ }^{4}$. The knowledge and attitude of medical students towards forensic autopsy is a significant factor that influences 
the quality of autopsy reports 5 . Therefore present study was conducted to ascertain the knowledge, attitude and awareness of medical students towards medico-legal autopsy examination ${ }^{6}$.

\section{Materials and Method}

To assess the knowledge and attitude of medical students towards medico-legal autopsy, a cross sectional study was conducted in January 2020 on 150 medical students of $2^{\text {nd }}$ year MBBS at department of Forensic Medicine and Toxicology at BVDU \& MC, Sangli, Maharashtra. Before starting the study, written approval from the institutional ethics committee was obtained. The questionnaires consisting of 16 questions related to the knowledge and attitude towards medico-legal autopsy were distributed to the aforementioned participants. Medical students of $2^{\text {nd }}$ year MBBS who refused to participate or were not available on second visit were excluded from the study.

\section{Results}

Total 150 medical students of $2^{\text {nd }}$ year MBBS were selected for this present study and the following observations are made.

\section{Questionnaires:}

\begin{tabular}{|c|c|}
\hline $\begin{array}{l}\text { 1. Medico- legal post-mortem examination is mandatory in all } \\
\text { unnatural, sudden, unexpected and suspicious death }\end{array}$ & $\begin{array}{l}\text { a. Yes }(n=145,96.66 \%) \\
\text { b. } \operatorname{No}(n=5,3.3 \%)\end{array}$ \\
\hline $\begin{array}{l}\text { 2. Is there any utility of taking out of viscera for histo-pathological } \\
\text { examination and toxicological analysis in medico legal autopsy? }\end{array}$ & $\begin{array}{l}\text { a. Yes }(n=137,91.33 \%) \\
\text { b. No }(n=13,8.66 \%)\end{array}$ \\
\hline 3. Post-mortem examination & $\begin{array}{l}\text { a. Done to know the cause of death }(n=145,96.66 \%) \\
\text { b. Harassment to the relative of the deceased }(n=3,2.0 \%) \\
\text { c. Mere legal formality }(n=2,1.33 \%)\end{array}$ \\
\hline $\begin{array}{l}\text { 4. Do you think that autopsy helps in solving crimes and give } \\
\text { important information to police? }\end{array}$ & $\begin{array}{l}\text { a. Yes }(\mathrm{n}=148,98.66 \%) \\
\text { b. No }(\mathrm{n}=2,1.33 \%)\end{array}$ \\
\hline 5. Student should attend more post-mortem examination? & $\begin{array}{l}\text { a. Yes }(n=142,94.6 \%) \\
\text { b. No }(n=8,5.4 \%)\end{array}$ \\
\hline $\begin{array}{l}\text { 6. Wished to have post-mortem examination on self/relative when } \\
\text { required? }\end{array}$ & $\begin{array}{l}\text { a. Yes }(n=114.76 \%) \\
\text { b. No }(n=36,24 \%)\end{array}$ \\
\hline $\begin{array}{l}\text { 7. Given a chance would you choose not to watch post-mortem } \\
\text { examination at all? }\end{array}$ & $\begin{array}{l}\text { a. Yes }(n=140,93.33 \%) \\
\text { b. No }(n=10,6.66 \%)\end{array}$ \\
\hline 8. The utility of post-mortem examination in medical education? & $\begin{array}{l}\text { a. Yes }(n=144,96.66 \%) \\
\text { b. } \operatorname{No}(n=5,3.33 \%)\end{array}$ \\
\hline $\begin{array}{l}\text { 9. Whether doing post-mortem examination causes disfigurement of } \\
\text { the body? }\end{array}$ & $\begin{array}{l}\text { a. Yes }(n=80,53.33 \%) \\
\text { b. No }(n=70,46.66 \%)\end{array}$ \\
\hline 10. Post-mortem examination is disrespect to human body? & $\begin{array}{l}\text { a. Yes }(n=140,93 \%) \\
\text { b. No }(n=10,7 \%)\end{array}$ \\
\hline $\begin{array}{l}\text { 11. Should medical students actively participate in performing } \\
\text { autopsies? }\end{array}$ & $\begin{array}{l}\text { a. } \text { Yes }(n=139,92.66 \%) \\
\text { b. } \quad \text { No }(n=11,7.33 \%)\end{array}$ \\
\hline $\begin{array}{l}\text { 12. Can relatives request the doctors for doing autopsy } n \text { without } \\
\text { police inquest report? }\end{array}$ & $\begin{array}{l}\text { a. Yes }(n=140,93.33 \%) \\
\text { b. No }(n=10,6.66 \%)\end{array}$ \\
\hline $\begin{array}{l}\text { 13. Do you think body can be handed over to the relatives without } \\
\text { post-mortem examination if the cause of death is known in a } \\
\text { MLC Cases? }\end{array}$ & $\begin{array}{l}\text { a. Yes }(n=55,36.33 \%) \\
\text { b. } \operatorname{No}(n=95,63.33 \%)\end{array}$ \\
\hline $\begin{array}{l}\text { 14. Before conducting the medico legal autopsy following is } \\
\text { necessary. }\end{array}$ & $\begin{array}{l}\text { a. Consent of relatives is must }(n=20,13.33 \%) \\
\text { b. Inquest report from investing officer is must }(n=63,42 \%) \\
\text { c. Request letter from investigating officer }(n=25,16.66 \%) \\
\text { d. None of the above }(n=42,28 \%)\end{array}$ \\
\hline
\end{tabular}




\begin{tabular}{|l|l|}
\hline \multirow{3}{*}{$\begin{array}{l}\text { 15. During medico legal autopsy following procedure should be } \\
\text { followed }\end{array}$} & a. External examination only $(\mathrm{n}=142,94.66 \%)$ \\
\hline & b. Internal examination only $(\mathrm{n}=3,2 \%)$ \\
\hline & c. Both external and internal examination $(\mathrm{n}=5,3.33 \%)$ \\
\hline \multirow{2}{*}{ 16. Virtual autopsy is a new form of post-mortem examination? } & $\begin{array}{l}\text { a. Yes }(\mathrm{n}=48,32 \%) \\
\text { b. No }(\mathrm{n}=13,8.66 \%) \\
\text { c. Don't know }(\mathrm{n}=89,59.33 \%)\end{array}$ \\
\hline
\end{tabular}

Majority of the study population (96.66\%) agreed that need of autopsy in all unnatural, sudden, unexpected and suspicious death is mandatory. Out of 150 students $137(91.33 \%)$ students are aware of collection of viscera for histo-pathological and toxicological analysis is useful. Majority of the study population 145(96.66\%) says post mortem examination is done to know the cause of death, where as $2 \%$ of the study population says it is a harassment to the relative of the deceased and $1.33 \%$ of the study population thinks that it is a mere legal formality. It is also observed that $98.66 \%$ of study population agreed that autopsy helps in solving crimes and gives important information to police.

Majority of the students agreed that they should attend a greater number of autopsies $(94.66 \%)$ and wished to have post-mortem examination on self/ relatives when required. Most of the students (96.66\%) say that post-mortem examination is useful in medical education. 80 students (53.33\%) think that autopsy causes disfigurement of body and 140 students (93\%) think that autopsy is disrespect to human body. Majority of the study population (92.66\%) agreed that students should actively participate in performing autopsies.

Most of the study population (93.33\%) thinks that no relatives can request the doctor for doing autopsy without police inquest report. Majority of the study population $(63.33 \%)$ thinks that body cannot be handed over to the relatives without autopsy in medico-legal cases. 13.33\% of the study population thinks that consent from relatives is must before conducting autopsy. $42 \%$ of the study population thinks inquest is must and $16.66 \%$ of study population thinks that request letter from investigating officer is must.

Majority of the study population (94.66\%) thinks that only external examination is followed in autopsy, where as $3.2 \%$ of study population thinks that only internal examination should be followed and just $2 \%$ of study population thinks that both external and internal examinations should be followed during autopsy. Majority of the study population (59.33\%) is not aware of virtual autopsy, where as $32 \%$ of study population says virtual autopsy is the new form of post-mortem examination.

\section{Discussion}

The medico-legal examination of dead body is instrumental in accurately establishing the cause and manner of death. It plays a crucial role in acquiring medical knowledge, and has been an important part of medical education for centuries. In this present study we have tried to know the knowledge and attitude of medical students towards the medico-legal autopsy.

In the present study it is observed that the knowledge of the necessity of the forensic autopsy in unnatural, sudden unexpected and suspicious death cases and for the utility of using viscera for the histo-pathological and toxicological analysis was present with $96.66 \%$ and $91.33 \%$ of the medical students respectively. These findings were similar to results of the study conducted by Madhusudhan $\mathrm{S}^{6}$ and Murugesa $\mathrm{B}^{7}$.

It is also observed that majority of the study population agreed that autopsy will help in solving crimes and give important information to the investigating officer. These findings are similar to the study conducted by Inderjit $\mathrm{SB}^{8}$.

In this present study it is also observed that majority of the medical students think that an autopsy is not the harassment to the relatives of the deceased. This observation is in agreement with the study conducted by Ahmad $\mathrm{M}$ and others. ${ }^{9} \mathrm{But}$ in our study majority of the students are not aware of virtual autopsy as a new form of post mortem examination, this finding is not in agreement with the study conducted by Ahmad M and others $^{9}$.

In this present study we have observed that majority of the study population agreed that postmortem examination is done to know the cause of death. These findings were similar to results of the study conducted by Madhusudhan $\mathrm{S}^{6}$. 
The results of the present study concluded that majority of the medical students had sufficient knowledge about the procedures and had positive attitude towards observing the autopsies. These findings are similar to the study conducted by Shamshuddin RK and others ${ }^{4}$.

In this present study we have observed that majority of the study population agreed on the importance of autopsy in medical education curriculum and are in support of watching and participating in a greater number of autopsies. These findings are in agreement with the study conducted by Jadeep CJ and others ${ }^{10}$. But in our study majority of the students believed that postmortem examination is disrespect to the human body, this finding is not in agreement with the study conducted by Jadeep $\mathrm{CJ}^{10}$.

\section{Conclusion}

Toassess theknowledgeand attitude ofundergraduate medical students towards medico-legal autopsy, a cross sectional study was conducted at BVDU \& MC, Sangli, Maharashtra. The findings of this present study show that undergraduate medical students have a reasonable knowledge and positive attitude about medico-legal autopsy. But the knowledge, awareness and positive attitude alone may not be enough for increasing the post-mortem/autopsy as an education tool, unless they acquire the skills required for the procedure as currently, they are not provided with any training during their medical curriculum. Hence, we recommend revising the forensic medicine curriculum and for increased training in the autopsy procedure and other medico-legal issues during their clinical and internship years so that medical students will be able to make rational conclusions in criminal and other medico- legal cases.

\section{Conflict of Interest: Nil}

\section{Source of funding: Self}

Ethical clearance: Taken from IEC, BVDUMC \& H, SANGLI.

\section{Reference}

1. G Venkat Rao, S Krishna Prasad. Autopsy Perception and Attitudes of Undergraduate Medical Students in South India: A Questionnaire Survey. IAIM. 2016;3(10):204-11.
2. Ravi Rautji, Avishek Kumar, C Behera. Attitudes of Medical Students towards Medico-legal/ Clinical Autopsy. J Indian Acad Forensic Med. 2013;35(4):358-61.

3. Aman Kumar, Sanjeev Kumar, Nikhil Goel3, Saroj K Ranjan, Mukesh Prasad, Pinki Kumari. Attitude of Undergraduate Medical Students towards Medico-Legal Autopsies at I.G.I.M.S., Patna, Bihar. Int J Med Res Prof.2018Nov;4(6):132-5.

4. Shamshuddin R Kakkeri. Khazi Mudabbir Ahmed, Sultan Rizwan Ahmad, Reshma Khan. Knowledge and attitude of medical students toward medicoLegal autopsy. IP International Journal of Forensic Medicine and Toxicological Sciences. 2018;3(1):811.

5. Virendar Pal Singh, Gautam Biswas. Knowledge and Attitude of Medical Students and Interns toward Forensic Autopsy. J Indian Acad Forensic Med.2014;36(1):9-12.

6. Madhu Sudhan S, Hemanth Raj MN. Current Status of Knowledge, attitude and awareness of medical students on Forensic autopsy in Tumkur district of Karnataka. Indian Journal of Forensic Medicine \& Toxicology. 2019;13(1):131-4.

7. Murugesa Bharathi, Chan Loo, Venkatesan M, Priyamvada Sharma, Virender K Chhoker, Sanjeev Kumar Khichi, Dynes Kaluba. Current status of perceptions towards autopsy and post mortem examination among medical undergraduate students. Online International Journal of Medical and Social Sciences. 2015;1(3):66-71.

8. Inderjit Singh Bagga, Vipin Goyal,Abhishek Singh, Hitesh Chawla, Shewtank Goel, Sakshi Sharma. Knowledge towards post-mortem examination and reasons for not specializing in morbid anatomy: study among medical undergraduate students. International Journal of Research in Medical Sciences. 2016;4(7):2792-5.

9. Ahmad M, Rahman MF, Rahman FN, Rahman MA. Knowledge and Attitude of 3rd Year Medical Students regarding Post Mortem Examination. JAFMC Bangladesh. 2016;12(2):9-14.

10. Jadeep C Jadav, Bhaskar N Patel, Kalpesh A shah, Rakesh N Tandon. Knowledge and Attitude of Medical Students on Forensic Autopsy in Ahmedabad City. J Indian Acad Forensic Med. 2013;35(1):26-8. 